This item was submitted to Loughborough's Research Repository by the author.

Items in Figshare are protected by copyright, with all rights reserved, unless otherwise indicated.

\title{
Defining the sustainable building design process: methods for BIM execution planning in the UK
}

\section{PLEASE CITE THE PUBLISHED VERSION}

http://dx.doi.org/10.1108/IJESM-04-2014-0005

\section{PUBLISHER}

(C) Emerald Group Publishing Limited

VERSION

AM (Accepted Manuscript)

\section{LICENCE}

CC BY-NC-ND 4.0

\section{REPOSITORY RECORD}

Zanni, Maria A., Robby Soetanto, and Kirti Ruikar. 2019. "Defining the Sustainable Building Design Process: Methods for BIM Execution Planning in the UK". figshare. https://hdl.handle.net/2134/16500. 


\title{
Defining the Sustainable Building Design Process: Methods for BIM Execution Planning in the UK
}

\author{
Maria-Angeliki Zanni, Robby Soetanto, Kirti Ruikar \\ School of Civil and Building Engineering \\ Loughborough University, UK
}

\begin{abstract}
Purpose - Building performance analysis is usually performed after the design and construction documents are produced resulting in lost opportunities. The purpose of this research is to develop a BIM-enabled sustainable design process model that identifies critical actions in the design process along with the information and level of detail that facilitate an informed and timely decision.

Design/methodology/approach - A number of research methods have been adopted; these include extensive literature review and eleven in-depth interviews with industry practitioners (sustainable building design experts, early BIM adopters).

Findings - Project delivery methods have a significant effect on the sustainable outcome of buildings. The development of a structured process can assist sustainable design practice among building professionals. Learning from implemented projects, that have utilised BIM processes, facilitates the scope of creating this process and advises future projects in order to prevent failures. Process mapping is essential to streamline the process, support key project processes and help the design team manage their own responsibilities and deliverables required by them.

Originality/value - The identification of the gap and the need for a structured process for sustainable building design for BIM execution is discussed. The synergies that exist between BIM, building performance modelling, BREEAM assessment and the RIBA Plan of Work are shown. The effect that project delivery has on sustainable design outcome has been established. A coordinated collaborative design process model is presented based on the findings from interviewing early adopters.

Keywords Sustainable building design, Performance modelling, Assessment methods, , Building Information Modelling (BIM), RIBA Plan of Work 2013, Process mapping, Interdisciplinary collaboration
\end{abstract}

Paper type Research paper

\section{Introduction}

Currently, sustainable performance of buildings has become a major concern among AEC/O (Architecture, Engineering, Construction and Operation) professionals for a variety of reasons. Those include the growing awareness concerning the impact of construction on environmental deterioration which has also led to a number of measures such as building legislation and assessment in addition to a number of national and regional drivers and targets (Schlueter and Thesseling, 2009). The overall goal is to reduce the environmental impact of buildings while enhancing human comfort and health. In order to address this issue, many countries and international organisations have initiated rating systems to assess sustainable construction (Azhar et al., 2011; Haapio and Viitaniemi, 2008). Some examples are United Kingdom's BREEAM (Building Research Establishment's Environmental Assessment 
Method), United States' LEED (Leadership in Energy and Environmental Design), Australia's GREEN STAR, Japan's CASBEE (Comprehensive Assessment System for Building Environmental Efficiency), and Germany's Passivhaus (Passive House Institute Darmstadt). These assessment methods are currently used as frameworks for sustainable design by AEC professionals although they provide no consideration of the critical issues concerning sustainability during the design process.

Building professionals utilise performance analysis tools to predict and quantify aspects of sustainability from early design stages and significantly ameliorate both quality and cost during a building's life cycle. Despite the proven benefits of these tools (Schlueter and Thesseling, 2009; Azhar et al., 2008; Azhar, 2011; Stumpf et al., 2009; Geyer, 2012; Çetiner, 2010; Gerber et al., 2012; Mourshed et al., 2003; Parasonis et al., 2012; Ding, 2008; Attia et al., 2009; Brahme et al., 2001), their practice should be utilised with careful consideration of the information requirements and the expected outputs of certain types of analysis. BIM (Building Information Modelling) software addresses this issue by promoting the integration of multi-disciplinary information and presents an opportunity to use accurate inputs to perform performance analysis. This practice increases the probability of more reliable results of these analyses. BIM is considered to be one way to address the deep-rooted fragmentation problem in the AEC industry by being a computer intelligible approach to exchange building information between disciplines during design and construction process (Sacks et al., 2010).

Aligning the above elements (sustainability certification, building performance modelling, BIM collaboration) into a structured process, can assist building professionals understand what is expected from them and improve coordination amongst different principles. In the UK, the RIBA (Royal Institute of British Architects) Plan of Work, which was originally published in 1964, has been widely accepted as a standard method of operation (Cooper et al., 2008). The Plan of Work 2013 (RIBA, 2013) aims to address the issues of coordination and fragmentation with the use of BIM and the concept of the collaborative project team. Following the recommendations by the BIM Working Group, the government has mandate the use of fully collaborative 3D BIM for its projects by 2016 (BIS, 2011). Despite that fact, the know-how is still missing from these processes; sustainability considerations are limited to a checklist and are not integrated in the RIBA Plan of Work's core objectives

The need for a fully collaborative 3D BIM will lead towards a shift in traditional business processes. This shift necessitates major changes at various levels in order to adapt to the new technological improvements (software, hardware and networks). This fact raises the need to specify the process of sustainability performance analysis within BIM-collaboration. The challenge that this incorporation faces is the effective coordination of all the available entities (people, resources and information) which are necessary to achieve optimum results. The importance of process modelling is widely recognised in the research community; the main objective is to provide designers with high quality information on which to base their decisions (Dorador and Young, 2000). This paper is intended to present the methods used and the findings concerning the main requirements that constitute effective sustainability assessment within the building design stages based on lessons-learned and how-to knowledge from implemented projects. Informed decision-making among the design team can dramatically increase the likelihood of achieving sustainability targets (Mayer and DeWITTE, 1999).

\section{Background research}




\subsection{Overview}

This section presents the drivers, enablers and constraints of BIM-based sustainable assessment into collaborative design. In order to achieve the effective integration of the above elements for leaner design, the sub-processes and stakeholders' responsibilities need to be clarified. Defining these processes will accelerate and streamline the design process and encourage the adoption of the BIM widely into the construction industry.

The Green BIM report 2010 (McGraw-Hill, 2010), has revealed that practitioners believe that BIM has the potential to help achieve green objectives. The main obstacle that they encounter is in the use of BIM and the perception that existing tools are easier to use. Other reasons include the lack of knowledge about the availability and capabilities of the tools as well as been intimidated to use them (Yudelson, 2008). The NBS Sustainability Survey 2012 (NBS, 2012) illustrates the current state, attributes and practices of construction professionals in the UK. It shows that the majority of them acknowledge the importance of all three aspects of sustainability (environmental, economic and social). Despite that fact, practitioners do not necessarily feel confident about their skills and knowledge concerning sustainability. To overcome this shortcoming, adequate education about the concepts of sustainability and the available technology options is essential. Although practitioners know about the existence and benefits of the technology tools (BIM, building performance modelling, information communication technologies), the know-how is generally lacking. Competitive advantage is derived from the superior use and integration of tacit-knowledge (know-how), rather than explicit knowledge (knowing about) (Grant et al., 2010). This paper discusses the methods used and the findings concerning the main requirements that constitute effective sustainability assessment within the building design stages based on lessons-learned and how-to knowledge from implemented projects that BIM has been utilised.

\subsection{Sustainability indicators and building design criteria}

The general perception is that the meaning of sustainability in the construction industry is highly subjective and depends on an individual's experience and knowledge (Wong and Fan, 2013). The most widely accepted definition of sustainable development (SD) is given by the Brundtland Report (1987). The three main pillars of sustainability (environmental, social and economic) can be further analysed in a variety of perspectives which are human well-being, climate change mitigation, environment protection, fossil fuel replacement, security of supply and living standards (Clarke, 2012). The construction industry, as one of the main sectors of the national industry is expected to contribute more towards those aspects (Nofera and Korkmaz, 2010). One common interpretation for sustainable buildings focuses on the less use of virgin building materials and energy and the production of less pollution and waste (Szokolay, 2008). The sustainable building certification rating systems (BREEAM, LEED, GREEN STAR, CASBEE, Passivhaus) create a widely accepted set of design criteria for the performance of the whole building and for the effective comparison with other buildings (Fowler and Rauch, 2006). Even though each of these systems requires different performance goals, most of these systems take into account similar sustainable criteria such as energy consumption, material use, water efficiency and indoor visual and thermal comfort (Azhar et al., 2011). Although compliance to a sustainability rating system is not mandatory, it is beneficial to show that certain sustainability measures have been considered (Biswas and Tsung-Hsien Wang, 2008). 
Building simulation is a growing discipline since the 1960s and until today is constantly evolving. The importance of informed decisions from the early stages of design is widely accepted but designers find it difficult to utilise basic tools to assess the sustainability performance of buildings (Attia et al., 2009). Consequently, the level of adoption remains low (Khandokar et al., 2009) and the gap between the architects and the users of such tools is growing (Warren, 2002). The most significant barriers are people-related issues such as the lack of expertise, communication and organisational commitment as well as the fragmented roles and the resistance to change (Khandokar et al., 2009).

BIM offers the possibility to reduce repetitive work and discrepancies between building simulation models by integrating accurate information from a variety of disciplines into common data formats such as the Industry Foundation Classes (IFC), IFCXML and COBie. A number of schemes have also been developed for extracting the environmental data in a neutral format; the gbXML, ecoXML, greenbuildingXML are other interoperability standards that can enhance data integration. The use of these public, non-proprietary formats can facilitate the exchange of rich and useful information between project partners without loss of accuracy or design intent (Gupta et al., 2014). Kriegel and Nies (2008) indicate that BIM can aid in the following aspects of sustainable design: (i) building orientation (selecting a good orientation can reduce energy costs), (ii) building massing (to analyse building form and optimise the building envelope), (iii) daylighting analysis, (iv) water harvesting (reducing water needs in a building), (v) energy modeling (reducing energy needs and analysing renewable energy options can contribute to low energy costs), (vi) sustainable materials (reducing material needs and using recycled materials), (vii) site and logistics management (to reduce waste and carbon footprints) (Krygiel and Nies, 2008). Figure 1 illustrates the information flows and file formats between the most commonly used software applications for BIM-based performance analysis.

Managerial issues in construction information systems are found to be more influencing than technology issues (Jung and Kang, 2007) but very little is known about how these decisions are made to steer the design process (Jung and Joo, 2011; Cerovsek, 2011; Zerjav et al., 2013). Although a significant body of research has been conducted on topics related in BIM-aided collaborative design and the efficient use of BIM technology, there is little known about the incorporation of sustainable performance analysis into these processes. The main approaches of BIM and sustainability assessment integration are either frameworks for the effective use of existing tools collaborative or otherwise), new stand-alone assessment tools or a hybrid approach of creating new tools to assist co-ordination between different software (Barnes and Castro-Lacouture, 2009; Biswas and Krishnamurti, 2009; Schlueter and Thesseling, 2009; Bank et al., 2010; Welle et al., 2011; Geyer, 2012; Parasonis et al., 2012; Gerber et al., 2012; Bazjanac, 2008; Gupta et al., 2014; Howard and Björk, 2008; NBS, 2012). These new tools are either integrated into BIM software or extracting data in open exchange formats (IFC, gbXML, ecoXML) and manipulate them for performing their analysis.

Despite these efforts, there is still no comprehensive and structured process to assist professionals to perform sustainability analysis from the early stages of design so the talents of various building disciplines can be harnessed and optimum results achieved. Current technology options offer a unique opportunity to predict how a real structure will perform but, to practically implement it requires re-thinking the traditional methods of designing (Garber, 2009). So as tomove a step closer towards sustainable development (SD) assisted by the new technological improvements (software, hardware and networks) and adapt to BIM, there is a need to specify the process of sustainable performance analysis within BIM-collaboration. 


\section{Research methods}

\subsection{Overview}

The overall scope of the research is to complement the new RIBA Plan of Work 2013 with evidence from existing practice and contribute to its ongoing evolution. This choice has been made in the attempt to bridge the gap between common practice (RIBA Plan of Work) and the mandated fully collaborative BIM with experienced gained from early adopters in the area. The resulting process will serve as a route where the critical changes in the process can be identified. The constructed process is not meant to be prescriptive but aims to raise considerations during the design process and increase the understanding of sustainability by making explicit what is currently tacit among sustainability experts. These considerations help prevent lost opportunities to maximise the building's performance by highlighting critical issues at specific stages and the reasoning behind each decision. The objectives are both to inform the knowledge base system with examples of best practices and also identify the bottlenecks in the process to suggest improvements. Once the description is completed, it will to inform novice building practitioners and raise their performance to a level comparable to that of an expert (Mayer et al., 1995).

The interviews have been conducted in two phases. The first one (Phase One) serves to validate the concept of a standardised process and the second one (Phase Two) to understand the sub-processes that take place during BIM-enabled collaboration for sustainability assessment. The process models that have been developed combine the requirements of design stages of a sustainable building at different levels. This practice serves to understand the complex interrelationships between the elements described in the above section and identify enablers and constraints in the process. Two methods of the Integrated DEFinition (IDEF) language family have been utilised to overcome the individual limitations. First, the IDEF0 for function modelling and then the IDEF3 process description capture method. The IDEF0 is widely used in research community due to its clarity of modelling activities and information flows between them as products of those activities. However, the models cannot support information process flows or capture concurrent processes and there is no consideration of time (Mayer and DeWITTE, 1999). One the other hand, the IDEF3 method addresses these issues as it has been created for capturing descriptions about sequences of activities while identifying critical decision points or milestones of the process from different perspectives (Mayer et al., 1995).

\subsection{The IDEF0 method}

The IDEF0 method is using the ICOM (Input, Control, Output, and Mechanism) (Draft Federal Information Procesising Standards, 1993). Each side of the function box has a standard meaning in terms of box/arrow relationships. The side of the box with which an arrow interfaces reflects an arrows role. Arrows entering the left side of the box are inputs. Inputs are transformed or consumed by the function to produce outputs. Arrows entering the box on the top are controls. Controls specify the conditions required for the function to produce correct outputs. Arrows leaving a box on the right side are outputs. Outputs are the data or objects produced by the function. Arrows connected to the bottom side of the box present mechanisms. Upward pointing arrows identify some of the means that support the execution of the function. Other means may be inherited from the parent box. Mechanism 
arrows that point downward are call arrows. Call arrows enable the sharing of detail between models (linking them together) or between portions of the same model.

\subsection{The IDEF3 method}

The IDEF3 Process Description Capture Method was created specifically to capture descriptions of sequences of activities. The goal of the method is to provide a structured method that can be used to express the knowledge of domain experts for a particular system or organisation (Mayer et al., 1995). The method manages to remain simple while maintaining a high descriptive power (Dorador and Young, 2000). There are two types of IDEF3 schematics for two process knowledge acquisition strategies; the process schematics for a process-centered view of a scenario and the object schematics that support the graphical display of object-centered information. The boxes represent real world processes as happenings; those are referred to as units of behavior (UOB). The arrows that connect the boxes indicate precedence between actions. The junctions represent constraints and enable process branching. The junctions involve choices among multiple parallel or alternative subprocesses. The logical decisions include: and (\&), or (O), and exclusive or (X) and synchronous or asynchronous start and finish of the processes. The objects are represented as circles that represent their different states connected with arrows that have UOB's referents to indicate the entry, transition, state and exit conditions (Mayer et al., 1995). The IDEF3 notation is very useful for communicating with collaborators within a system. (Dorador and Young, 2000).

\subsection{The IDEF0 model}

In the light of the new RIBA Plan of Work 2013, an IDEF0 (Integration DEFinition language 0) (Draft Federal Information Processing Standards Publication 183, 1993 December 21) model has been created to map the BIM-based sustainable design process. The IDEF0 Parent Diagram (A-0) presented in Figure 2 is the top-level context diagram that describes the main Inputs, Outputs, Controls and Mechanisms that facilitate BIM-enabled Sustainable Design. The child diagram (A0) is always in the scope of the top-level diagram. The single function that is represented on the Parent Diagram (A-0) is decomposed into its major sub-functions in the Child Diagram (A0). The numbered arrows of A-0 diagram correspond to the boundary arrows of its Child Diagram (A0) as they are indicated in Figure 6. The letters I, C, O or M identify the arrow as an Input, Control, Output or Mechanism on the Parent box (0). These boundary arrows of the top-level diagram can be found at any stage at the decomposition diagram. For example, The Planning Application (O2 arrow) is one of the main outcomes of the Design Process shown in Figure 2; in Figure 3, it is shown as an output of phase 3, Developed Design, before the end of the whole process. Furthermore, the outcome of one stage can be either input or control for the next stage of the process. As depicted in Figure 3, the Final Project Brief that is an outcome of the Concept Design Development stage (A2 level) is a control for the preparation of the Developed Design (A3 level); that is, because it is not altered but the process while it guides it to happen.

In order to understand the interrelationships between the people, process and tools the boxes in Figure 3, each box of the Child Diagram (levels A1, A2, A3, A3 and A4) needs further decomposition to lower-level diagrams. Although this generic process outlines the main stages of the process, still it does not offer a comprehensive way on the inter-related practical elements and their relationships between them. Sustainability Aspirations (I3 arrow) for example have to acquire a more specific meaning regarding its context (BREEAM assessment, Code for Sustainable Homes, Passivhaus, or other specific client requirements). 
Additionally, the term "Project Team" becomes much more meaningful when tasks for each individual are specified; for example, the thermal analysis is usually performed by the M\&E engineer. Moreover, the level of detail of the information needed as well as the selection of software, the way of communication between stakeholders and the interaction with the client and users need further definition and clarification. For that reason, this model needs to be further analysed to its sub-processes in order to fully comprehend how the existing workflows can be optimised with the use of the available technology and the selection of the most suitable tools and people for the project. Another issue is that the method can be simplistic in an attempt to describe a more dynamic process of events. While IDEF0 is very useful to capture the main activities and expected outcomes of the process, it cannot capture the process flows. Due to the fact that the processes occur in a concurrent environment, it was considered beneficial to perform IDEF3 modelling to overcome the shortcomings of the IDEF0 method. The IDEF3 process view is adequate to map both the design process and the interactions between stakeholders and also to establish the relationship between design products, design system and design process (Dorador and Young, 2000).

\subsection{Validation interviews}

In order to verify the concept of the developed process model, a first round of interviews were conducted. Design management in the built environment projects is a research domain that addresses both high-level aspects as well as low-level aspects of the design process (Zerjav et al., 2013). To support the high-level description, a IDEF0 model, based on the RIBA Plan of Work 2013 suggested process, has been created in order to determine the main activities and the expected outcomes (products) of the process. After the IDEF0 model was developed, exploratory interviews were performed to validate and inform the model. Although the RIBA serves as a general framework, it can be interpreted in various ways depending on individual values, experience and expertise. The process that emerged is not a linear one; it involved more flexibility and concurrency of actions. Consequently, the " low-level process has been mapped with the IDEF3 method; this is because it offers more flexibility in the description that the IDEF0.

The purpose of the exploratory interviews at Phase One of the research has been essentially heuristic: to develop ideas and research hypothesis rather than gather facts and statistics. It was concerned with understanding whether the concept of a standardized process for sustainable building design fits within the existing business processes. . Initial questions set the context "classifying" questions. The funnel approach to questionnaire design starts off the module with a very broad question progressively narrows down the scope of the questions until the end when it comes to some very specific points. Open or free response questions have been implemented at this phase; they were not followed by any kind of choice so as to maintain the spontaneity and expressiveness (Oppenheim, 2000). It has been decided that the profiles of the interviewees have to comply with the following conditions:

1. Be an RIBA chartered architect

2. Undertake sustainable design

3. Utilise BIM in practice

By reason of proximity, the first choice was contacting organisations in the East Midlands, UK. The contact details of the sample were found though the RIBA Directory of UK Chartered Practices. During the search, only the practices that offered both Building Information Modelling (BIM) and Sustainable Design services were selected. The other method of approach was a more personal one; that was proven to be the most effective. It consisted of contacting people in attended webinars or be introduced by a common contact. If 
there was no reply to the first email, a reminder was sent after ten to fifteen days. Out of the fifty-one people contacted, there was a response number of seven but only five managed to conduct an interview (a response rate of $9.8 \%$ ). The interviews were conducted though phone conversation (2 interviews), Skype conference (2 interviews) and one was in person. The length of the interviews varied from one to two and a half hours. These methods were considered to be more efficient in terms of time and cost. This opportunistic approach to sample selection revealed the significant gap of relevant expertise in the UK construction industry. The interviewees' profiles are presented in Table 1.

The funnel approach was implemented and there were four stages to the interviews: the introductory questions, the transitional questions, the main questions and a closing one. The introductory questions were about some general facts about the size of the organisation and the size and types of projects usually undertaken. The transitional questions themes were:

- Experience with BIM and software choices;

- Methods for assessing sustainability in a project;

- Methods and means of collaboration and communication among stakeholders;

- Identified deficiencies in the transition towards BIM processes; and

- Main changes in assessing sustainability using BIM.

In the main part of the questionnaire, the IDEF0 diagram was introduced and explained. The interviewees were asked to identify the similarities and differences between current practice and the IDEF0 model and identify the main changes that are needed so the model could be implemented in practice. The rest of the questionnaire was divided in sections. Each section included questions for each design stage of the RIBA Plan of Work 2013. The themes of the questions included:

- Information requirements for exchange between stakeholders;

- Definition of sustainability aspirations and prioritisation of various aspects;

- Level of detail of information needed;

- Format of inputs and outputs; and

- Interaction with the client at each stage.

The final question was about their future aspirations concerning the emerging technologies (such as BIM) and the changes that should/could be made in order to be successfully incorporated into existing practice of sustainable building design. This research approach has informed the course of the research into the selection of the research focus areas and the adequate methods for the data collection strategy.

The Critical Decision Method (Klein et al., 1989) has been followed in Phase Two to elicit the expert knowledge and to develop the low-level IDEF3 processes. Its main applications are for developing expert systems in order to improve quality of human performance in decision-making tasks. The method distinguishes the "expert" and "novice" practitioner regarding their skills and experience. That happens by focusing on a specific incident (case base approach) and using semi-structured probing to adjust timing and wording to adapt the case.

The role of the expert in this study is defined as someone that has over 10 years' experience in sustainable design and has been involved in the design process of buildings that have achieved relevant awards such as the CIBSE Building Performance Award, UK Passivhaus Awards, RIBA Sustainability Award, BREEAM Outstanding and Sustainable Project of the Year. Out of the five people that have participated in the early stage of the research, only two have been identified as experts based on the above criteria and have agreed to continue to the next stage of the research. Targeted research has been undertaken to 
identify suitable experts. The challenges that this procedure encountered were that the people that successfully utilise BIM for sustainable design in the UK are very few in number and secondly they are hesitant to reveal confidential project information and empirical experience that are considered to give them competitive edge as early adopters of that approach. The experts' profiles and the case studies discussed are shown in Table 2. The statistics are as follows:

- Out of the 34 emails send to people that fulfilled the above criteria

- $6(17 \%)$ received autoreplies for been absent

- $2(6 \%)$ answered that they were not willing to participate due to heavy workload

- 4 (12\%) have agreed to participate in the research

- $6(17 \%)$ interviews have been conducted during this stage

\section{Discussion of findings}

\subsection{Phase One}

The interviews revealed a variety of problems due to lack of co-ordination during the implementation of a project. The main issue was the lack of understanding of sustainability and the variety of interpretations that hindering the clear set of goals from the beginning. A better definition is necessary and apart from that a common route that should be followed by the project team to guide the process (I-3). Guidelines for those, who are not specialists in sustainable design, must be set. The definition should be expanded from just a checklist to highlight what the outcome should be based on experience from implemented projects and the knowledge of what actually works and what does not. Hard evidence is required to create benchmarks for better sustainable future buildings (I-1).

Cultural and legal barriers appear to prevent collaboration. The unwillingness of certain stakeholders to participate from early stages in the process, unless they are bound by contract, was revealed. This is a crucial issue because, in order to successfully implement sustainability, certain matters need to be considered holistically and the input of a variety of experts is necessary. Training and education among building stakeholders could be the solution for them to appreciate the benefits of collaboration. The role of the occupant is also significant; occupants need to interact better with buildings by following a users' manual. The building design should be as simple as possible, intuitive and adaptable because people tend to override any system that they find too complex to operate. Collaboration between the project team and the users of the building is essential to ensure user comfort and the ability to predict the performance of the facility (I-1).

Continuity in technology was also highlighted as an important issue along with usability and accuracy of software. Continuity has been explained in terms of the seamless exchange of information between software applications. At the moment, data can be extracted from the information model to perform the analysis but after the analysis, the changes implemented cannot be integrated back into the initial model (I-2). Practitioners would also prefer simpler user interfaces but there is reluctance towards hidden assumptions from rapid energy modelling software; the 'black box' calculations of some tools raise serious concerns about their reliability (I-3, I-4). The findings have revealed low use of ICT (Information \& Communications Technology) for collaboration among project participants and there is no consideration of integrating sustainability considerations in that process. It appears that the gap between people and technology has increased and practitioners do not implement BIM to 
its fullest of capabilities despite its potential for improving coordination among building design and sustainability assessment.

There was mutual agreement among the interviewees that a defined route that gives guidelines during each step of the process would be beneficial for designers, not to give them the answers to their design problems but to indicate the considerations for each decision and stimulate the thinking of the crucial issues for making an informed decision. One of the experts stated that "a tool that shows in clear way the level of detail needed so as to make a decision on an accurate basis would be really useful” (I-3). While many rapid energy modelling tools follow the logic of a sequence of steps, they don't inform of the information required to make that decision. This 'black box' approach and blind dependence on the results from these calculations involve the chance to be misled for someone who is not knowledgeable (I-4). For the novice practitioner, the implications for each design decision need to be clarified. A holistic approach can serve this purpose of understanding the trade-off relationships that occur in design.

The most recent RIBA Job Book (9 $9^{\text {th }}$ edition, 2013) (Ostime, 2013) provides descriptions of the activities for each consultant but does not explain the necessary links between neither them nor with parts of the process (I-4). The inputs and outputs are described in a generic fashion where it is not specified which information is critical for each decision so it remains still open to interpretation. Another objection was that sustainability is not part of the core objectives but is been treated as an add-on checklist in the process. Sustainability consideration should be integrated in the main process concurrently with every other issue (I4). In addition, the milestones of the process are not specified, they are only limited into design reports and information exchanges at the end of each design stage. "It (the Plan of Work) should identify at what stage in a project it is crucial to make sustainability decisions because it obviously makes it more costly and more difficult to do afterwards” (I-3).

\subsection{Phase Two}

First, the experts have been asked to select a case study that they have utilised BIM and have achieved a BREEAM certification (Table 2). Then, they were asked to describe an incident that has had a significant effect on sustainability (either positive or negative). The follow up questions served to create a timeline of the event and understand the reasoning behind their decisions. The findings have proven the direct effect that project delivery methods have in achieving a sustainable building outcome. Lack of coordination and late involvement of stakeholders have been the main reasons that the design intent failed to be realised. The lack of a standard process for collaborative building design has resulted in unwanted outcomes in terms of sustainability. A more proactive approach should be employed in the design process and the best cross-discipline design solution needs to be selected as the way forward. As the design process becomes more complex, due to demanding performance specifications, task and team co-ordination become more crucial than ever.

The experts have indicated that the following factors are essential in achieving sustainable design:

- The client should be informed, with realistic expectations set from the start;

- The project participants should be involved from the beginning (as many as possible), clear roles and responsibilities should be established;

- The project delivery process should be reviewed and re-defined regularly as the project evolves. Contractual agreements and allocated tasks should be set from the begging and revised on a regular basis; 
- Several iterations/reviews between stakeholders are crucial (cyclic process among stakeholders - design disciplines). Everyday communication among disciplines is key for sustainable design; and

- A strong relationship should exist between the architect and the MEP/M\&E/services engineers.

The incidents described have been linked to certain BIM Uses that served to achieve credits of specific BREEAM criteria (Table 3). It has been made explicit from their decisionmaking process how they prioritise sustainability criteria and the interdependencies between them. Constraints such as regulations have also been stated. The responsible parties to undertake tasks at each stage were discussed as well as the information exchanges between stakeholders. The dialog that followed the discussion of the specific incident description, included the description of the generic process of concept design. That description served to determine the commonality of the events described in practice. It has been apparent that there were certain procedural rules that the experts followed in their common practice. These descriptions have informed the development of the IDEF3 model for concept design presented in Figure 4.

\subsection{BIM execution planning for sustainable building design}

Table 3 has been created by combining the findings from the interviews with the ones from the literature review. The Table shows an example of BREEAM Strategy for the "Energy" BREEAM category against RIBA Plan of Work Stages. The actions that are followed by a "(!)" require urgent attention at the stage indicated. The other columns show the associations of BREEAM criteria with: BIM Uses, Responsible Party, Priority (High/Medium/Low), Overlaps between targets, Standards and Documents, Software Resources, and Required Evidence to achieve credits. The BREEAM strategy worksheet can act as a communication tool between project participants in order to clarify the roles and responsibilities of each party early on in the design process. Another benefit of this approach is that it can assist timely decisions and eliminate redundant work in decision-making. However, the highly diverse managerial needs of each project necessitate critical thinking in the adoption of the guidelines presented (CIC, 2011).

During information exchanges between project participants, the level of detail of the information exchanged is critical for achieving sustainability goals. However, common practice revealed that the information exchanged were not adequate to serve the required purpose. A common, defined standard would solve this problem. In BIM execution planning, the LODs are critical because they represent the information included in the model at specific stages and are associated with the practical side of BIM implementation (Wu et al., 2014). The definition of LODs as "Level of Development" was published in the AIA E202 Building Information Modeling Protocol Exhibit (AIA, 2008) and updated in AIA G202-2013 Project Building Information Modeling Protocol (AIA, 2013). In the UK, the PAS 1192-2:2013 defines the LOD as "Levels of model detail" for graphical content and LOI (Levels of model information) for non-graphical content (BSI, 2013). RIBA has also introduced the Level of Design (LOD) in Assembling a Collaborative Project Team (Sinclair, 2013). Table 4 presents the research findings aligned with LODs. This comparison helps to establish the associations between the various definitions of LOD and the RIBA stages. More importantly, it suggests the information that is critical for sustainability analysis at each stage of design.

Figure 4 represents the low-level IDEF3 process of the process (2) “Concept Design” in the IDEF0 high-level process map. This model integrates the analysis discussed in the 
above sections. It defines the stakeholders' responsibilities, information exchanges, level of model development, type of file formats, concurrent processes, iterations, and time scale. The model has been created by combining the findings from the interviews into a streamlined and applicable process for multi-disciplinary sustainable building design. Each of these processes could be analysed into further sub-processes if necessary, until the BIM Uses are defined and understood. The process shows the critical action points and the associations between stakeholders' tasks. For example, BIM Use "Analyse Energy Performance”, which is found in the IDEF3 model, is linked to Ene01, En04, Ene06, Ene07, Ene08 BREEAM Categories (Table 3). Column "2 Concept Design" shows which categories need urgent attention at this stage. This method can assist to eliminate the bottlenecks in the process, as the information requirements are clearly defined and communicated among the design team. The process reveals the synergies that the experts have utilised to achieve sustainability targets by implementing innovative processes in project delivery.

\section{Conclusion}

To achieve an optimum sustainable design process, critical decisions should be considered timely in order to assess trade-off relationships between various aspects of design between building professionals' disciplines with varying aspirations. Considerations about how multi-disciplinary collaboration between stakeholders can assist into achieving a holistic approach to design, by considering these trade-off relationships, are essential. The purpose of this research is to develop a sustainable design process model and identify critical actions in the design process along with the information and level of detail that is associated to make a decision on an accurate basis. The goal is to make explicit what is currently tacit among sustainable design experts and increase understanding of the implications of certain design decisions at the overall design outcome. The interviews conducted have revealed the need for a structured collaborative process to assist coordination between building professionals so as to utilise technology capabilities and improve sustainable outcomes through common objectives. It is believed that learning from experience can facilitate the scope of creating a more detailed process and advise future projects in order to prevent failures.

This paper discusses the need for a standard business process for project delivery of sustainable buildings. It also presents the enablers and constraints for implementing sustainable design utilising BIM and sustainable assessment software tools and methods to map their interrelationships. The synergies between BIM, building performance software, BREEAM assessment and the RIBA Plan of Work 2013 are examined. The mapping methods presented can be powerful tools to understand the activities, products and resources of a process. This research is an effort to carry forward 'lessons learned' and 'how-to' knowledge from implemented projects so as to increase the chance of success for future ones. High-level and low-level approaches have been implemented for that reason utilising IDEF0 and IDEF3 schematics. IDEF0 and IDEF3 can give a clear view of the system of concurrency between the product, the process and the system.

The findings from the interviews have shown that project delivery planning has a significant effect on sustainable building outcome. The BREEAM strategy worksheet can act as a communication tool between project participants in order to clarify the roles and responsibilities of each party early on in the design process. An example of the BIM execution planning for sustainable building design is presented along with the model for project delivery for concept design stage. The next step of the research (Phase Three) is the 
development and evaluation of a prototype application that supports BIM execution planning for sustainable building design in the UK so as to bridge the gap between the existing and the desired design process of BIM-enabled sustainable design.

\section{References}

AIA (2013), AIA G202-2013 Project Building Information Modeling Protocol Form. . available at:http://www.aia.org/aiaucmp/groups/aia/documents/pdf/aiab099086.pdf (accessed 20 June ).

Anumba, C.J. and Ruikar, K. (2008), e-Business in construction, Wiley Online Library.

Attia, S., Beltrán, L., De Herde, A. \& Hensen, J. (2009), "Architect friendly: a comparison of ten different building performance simulation tools", Proceedings of IBPSA '09 Buildings Simulation Conference, pp. 204.

Azhar, S. (2011), "Building Information Modeling (BIM): Trends, Benefits, Risks, and Challenges for the AEC Industry", Leadership and Management in Engineering, vol. 11, pp. 241.

Azhar, S., Carlton, W.A., Olsen, D.andAhmad, I. (2011), "Building information modeling for sustainable design and LEED ${ }^{\circledR}$ rating analysis", Automation in Construction, vol. 20, no. 2, pp. 217-224.

Azhar, S., Nadeem, A., Mok, J.Y. and Leung, B.H. (2008), "Building information modeling (BIM): A new paradigm for visual interactive modeling and simulation for construction projects", Proc., First International Conference on Construction in Developing Countries, pp. 435.

Bank, L.C., McCarthy, M., Thompson, B.P. and Menassa, C.C. (2010), "Integrating BIM with system dynamics as a decision-making framework for sustainable building design and operation", Proceedings of the First International Conference on Sustainable Urbanization (ICSU).

Barnes, S. and Castro-Lacouture, D. (2009), "BIM-enabled integrated optimization tool for LEED decisions", 2009 ASCE International Workshop on Computing in Civil Engineering, June 24-27, 2009, Austin, TX.

Bazjanac, V. (2008), "IFC BIM-based methodology for semi-automated building energy performance simulation", Proc.of CIB-W78.

Becerik-Gerber, B. and Kensek, K. (2009), "Building information modeling in architecture, engineering, and construction: emerging research directions and trends", Journal of Professional Issues in Engineering Education and Practice, vol. 136, no. 3, pp. 139-147.

BIS (2011), "BIM management for value, cost and carbon improvement", A report commissioned by the Department of Business, Innovation and Skills.

Biswas, T. and Krishnamurti, R. (2009), "Framework for Supporting Sustainable Design", School of Architecture, pp. 46.

Biswas, T. and Tsung-Hsien Wang, R.K. (2008), "Integrating sustainable building rating systems with building information models".

Brahme, R., Mahdavi, A., Lam, K. and Gupta, S. (2001), "Complex building performance analysis in the early stages of design", Seventh International IBPSA Conference, pp. 661.

BSI, (2013), "Specification for information management for the capital/delivery phase of construction projects using building information modelling” PAS 1192-2:2013,CIC.

Cerovsek, T. (2011), "A review and outlook for a 'Building Information Model'(BIM): A multi-standpoint framework for technological development", Advanced engineering informatics, vol. 25, no. 2, pp. 224-244.

Çetiner, O. (2010), "A Review of Building Information Modeling Tools from an Architectural Design Perspective", Handbook of Research on Building Information Modeling and Construction Informatics: Concepts and Technologies, pp. 19.

CIC. (2011), BIM Project Execution Planning Guide Version 2.1. Pennsylvania State University: CIC Research Group. 
CIC/BIM Pro (2013), Building Information Model (BIM) Protocol. Standard Protocol for use in projects using Building Information Models. First edition 2013. available at: http://www.cic.org.uk/publications/(accessed 30 July 2014).

Clarke, J. (2012), Lecture on Integrated Building Performance Simulation. Loughborough University, United Kingdom.

Cooper, R., Aouad, G., Lee, A., Wu, S., Fleming, A. and Kagioglou, M. (2008), Process management in design and construction, Wiley-Blackwell.

Crawley, D.B., Hand, J.W., Kummert, M. and Griffith, B.T. (2008), "Contrasting the capabilities of building energy performance simulation programs", Building and Environment, vol. 43, no. 4, pp. 661-673.

Ding, G.K. (2008), "Sustainable construction— The role of environmental assessment tools", Journal of environmental management, vol. 86, no. 3, pp. 451-464.

Dorador, J. and Young, R.I. (2000), "Application of IDEF0, IDEF3 and UML methodologies in the creation of information models", International Journal of Computer Integrated Manufacturing, vol. 13, no. 5, pp. 430-445.

Draft Federal Information Processing Standards Publication 183 (1993, December 21), INTEGRATION DEFINITION FOR FUNCTION MODELING (IDEF0).

Fowler, K.M. and Rauch, E.M. (2006), Sustainable building rating systems summary.

Garber, R. (2009), "Optimisation Stories: The Impact of Building Information Modelling on Contemporary Design Practice", Architectural Design, vol. 79, no. 2, pp. 6-13.

Gerber, D.J., Lin, S.E., Pan, B.P. and Solmaz, A.S. (2012), "Design optioneering: Multidisciplinary design optimization through parameterization, domain integration and automation of a genetic algorithm", Proceedings of the 2012 Symposium on Simulation for Architecture and Urban Design Society for Computer Simulation International, , pp. 11.

Geyer, P. (2012), "Systems modelling for sustainable building design", Advanced Engineering Informatics.

Glaser, B.G. and Strauss, A.L. (2009), The discovery of grounded theory: Strategies for qualitative research, Transaction Books.

Grant, K., Hackney, R. and Edgar, D.A. (2010), Strategic information systems management, Cengage Learning Business Press.

Gupta, A., Cemesova, A., Hopfe, C.J., Rezgui, Y. and Sweet, T. (2014), "A conceptual framework to support solar PV simulation using an open-BIM data exchange standard", Automation in Construction, vol. 37, pp. 166-181.

Haapio, A. and Viitaniemi, P. (2008), "A critical review of building environmental assessment tools", Environmental Impact Assessment Review, vol. 28, no. 7, pp. 469482.

Howard, R. and Björk, B. (2008), "Building information modelling-Experts’ views on standardisation and industry deployment", Advanced Engineering Informatics, vol. 22, no. 2, pp. 271-280.

Jung, Y. and Joo, M. (2011), "Building information modelling (BIM) framework for practical implementation", Automation in Construction, vol. 20, no. 2, pp. 126-133.

Jung, Y. and Kang, S. (2007), "Knowledge-based standard progress measurement for integrated cost and schedule performance control", Journal of Construction Engineering and Management, vol. 133, no. 1, pp. 10-21.

Khandokar, F., Price, A., Paranagamage, P., Mourshed, M., Austin, S. and Moobela, C. (2009), "Barriers to the adoption of sustainability assessment tools in strategic decision making".

Klein, G.A., Calderwood, R. and MacGregor, D. (1989), "Critical decision method for eliciting knowledge. Systems", Man and Cybernetics, IEEE Transactions on, vol. 19, no. 3, pp. 462-472.

Krygiel, E. and Nies, B. (2008), Green BIM: successful sustainable design with building information modeling, Wiley Publishing, Indianapolis,Sybex.

Lawson, B. (2006), How designers think: the design process demystified, Routledge. 
Maile, T., Fischer, M. and Bazjanac, V. (2007), "Building energy performance simulation tools-a life-cycle and interoperable perspective", Center for Integrated Facility Engineering (CIFE) Working Paper, vol. 107.

Mayer, R.J. and DeWITTE, P.S. (1999), "Delivering Results: Evolving BPR from art to engineering" in Business Process Engineering Springer, pp. 83-129.

Mayer, R.J., Menzel, C.P., Painter, M.K., Dewitte, P.S., Blinn, T. and Perakath, B. (1995), Information integration for concurrent engineering (IICE) IDEF3 process description capture method report.

McGraw_Hill Construction (2010), SmartMarket Report: Green BIM - How Building Information Modeling is Contributing to Green Design and Construction.

Mourshed, M., Kelliher, D.andKeane, M. (2003), "ArDOT: a tool to optimise environmental design of buildings".

NBS (2012), National BIM Report 2012, London: National Building Specification.

Nofera, W. and Korkmaz, S. (2010), "Design Process Integration for Sustainable, High Performance Buildings", Proceedings Editors.

Ostime, N. (2013), RIBA Job Book (9 ${ }^{\text {th }}$ edition), RIBA Publishing, ISBN: 9781859464960.

Parasonis, J., Keizikas, A. and Kalibatiene, D. (2012), "The relationship between the shape of a building and its energy performance", Architectural Engineering and Design Management, vol. 8, no. 4, pp. 246-256.

Redmond, A., Hore, A., Alshawi, M. and West, R. (2012), "Exploring how information exchanges can be enhanced through Cloud BIM", Automation in Construction, vol. 24, pp. 175-183. RIBA (2013), RIBA Plan of Work 2013 [Homepage of RIBA], available at: http://www.ribaplanofwork.com/ (accessed 20 January 2014).

RIBA (2012), BIM Overlay to the RIBA Plan of Work.

Sacks, R., Kaner, I., Eastman, C.M. and Jeong, Y. (2010), "The Rosewood experimentBuilding information modelling and interoperability for architectural precast facades", Automation in Construction, vol. 19, no. 4, pp. 419-432.

Schlueter, A. and Thesseling, F. (2009), "Building information model based energy/exergy performance assessment in early design stages", Automation in Construction, vol. 18, no. 2, pp. 153-163.

Sinclair, D. (2013). Assembling a Collaborative Project Team: Practical tools including Multidisciplinary Schedules of Services. RIBA Publishing, ISBN 9781859464977.

Strauss, A. and Corbin, J. (1994), "Grounded theory methodology", Handbook of qualitative research, , pp. 273-285.

Stumpf, A., Kim, H. and Jenicek, E. (2009), "Early design energy analysis using bims (building information models)", Construction Research Congress.

Succar, B. (2009), "Building information modelling framework: A research and delivery foundation for industry stakeholders", Automation in Construction, vol. 18, no. 3, pp. 357-375.

SuperBuildings (2011), Deliverable 3.3: Needs, levels and potentials of integrating SB assessment and benchmarking with BIMs.

Szokolay, S.V. (2008), Introduction to architectural science: the basis of sustainable design, Architectural Press.

Vakili-Ardebili, A. and Boussabaine, A.H. (2010), "Ecological Building Design Determinants", Architectural Engineering and Design Management, vol. 6, no. 2, pp. 111-131.

Warren, P. (2002), "Bringing simulation to application, IEA ECBCS Annex 30".

Welle, B., Haymaker, J. and Rogers, Z. (2011), "ThermalOpt: A Methodology for BIM-Based Passive Thermal Multidisciplinary Design Optimization", Center for Integrated Facility Engineering Technical Report, no. 200.

Wong, K. and Fan, Q. (2013), "Building information modelling (BIM) for sustainable building design", Facilities, vol. 31, no. 3/4, pp. 138-157.

Wu, W. and Issa, R.R.A., (2014). "BIM Execution Planning in Green Building Projects: LEED as a Use Case". Journal of Management in Engineering . ASCE. Yudelson, J. 
(2008), Green Building Through Integrated Design (GreenSource Books)(e-book), McGraw-Hill Professional.

Zerjav, V., Hartmann, T. and Achammer, C. (2013), "Managing the process of interdisciplinary design: identifying, enforcing, and anticipating decision-making frames", Architectural Engineering and Design Management, vol. 9, no. 2, pp. 121-133. 
Table 1: Interviewees' profiles

\begin{tabular}{|c|c|c|c|c|c|}
\hline $\begin{array}{l}\text { Interviewee - } \\
\text { Number }\end{array}$ & $\begin{array}{l}\text { Design } \\
\text { experience }\end{array}$ & $\begin{array}{l}\text { National } \\
\text { Classification } \\
\text { of } \\
\text { organisation }\end{array}$ & $\begin{array}{l}\text { Types of } \\
\text { construction } \\
\text { Projects }\end{array}$ & $\begin{array}{l}\text { Size of } \\
\text { Projects } \\
\text { (cost) }\end{array}$ & $\begin{array}{l}\text { BIM } \\
\text { maturity }\end{array}$ \\
\hline I-1 & 17 years & Medium & $\begin{array}{l}\text { Industrial, } \\
\text { commercial, } \\
\text { workplace, } \\
\text { education, } \\
\text { residential, } \\
\text { healthcare }\end{array}$ & $\begin{array}{l}£ 1 \text { to } £ 50 \\
\text { million }\end{array}$ & $\begin{array}{l}\text { Level } 1 \\
\text { (Microstation, } \\
\text { Ecosim) }\end{array}$ \\
\hline I-2 & 19 years & Medium & $\begin{array}{l}\text { School, leisure, } \\
\text { transport, } \\
\text { commercial, } \\
\text { master plans, } \\
\text { military } \\
\text { defense work, } \\
\text { residential }\end{array}$ & $\begin{array}{l}£ 1 \text { to } £ 50 \\
\text { million }\end{array}$ & $\begin{array}{l}\text { Level } 1 \\
\text { (Autodesk } \\
\text { Revit) }\end{array}$ \\
\hline I-3 & 16 years & $\begin{array}{l}\text { SME (small \& } \\
\text { medium } \\
\text { enterprises) }\end{array}$ & $\begin{array}{l}\text { Higher } \\
\text { education, } \\
\text { primary } \\
\text { education, } \\
\text { nursery, } \\
\text { housing }\end{array}$ & $\begin{array}{l}£ 0.5 \text { to } £ 20 \\
\text { million }\end{array}$ & $\begin{array}{l}\text { Level } 2 \\
\text { (Autodesk } \\
\text { Revit) }\end{array}$ \\
\hline I-4 & 16 years & SME & $\begin{array}{l}\text { Education, } \\
\text { public, housing, } \\
\text { health }\end{array}$ & $\begin{array}{l}£ 0.5 \text { to } £ 20 \\
\text { million }\end{array}$ & $\begin{array}{l}\text { Level } 2 \\
\text { (Autodesk } \\
\text { Revit) }\end{array}$ \\
\hline I-5 & 20 years & Medium & $\begin{array}{l}\text { Housing, } \\
\text { education, } \\
\text { health, sport } \\
\text { and leisure }\end{array}$ & $\begin{array}{l}£ 250 \mathrm{k} \text { to } £ 38 \\
\text { million }\end{array}$ & $\begin{array}{l}\text { Level } 1 \\
\text { (Autodesk } \\
\text { Revit) }\end{array}$ \\
\hline
\end{tabular}

\footnotetext{
${ }^{1}$ http://www.theb1m.com/videos/bim-maturity-easy-as-1-2-3
} 
Table 2: Experts' profiles and related case studies

\begin{tabular}{|l|l|l|l|}
\hline \multicolumn{2}{|l|}{ Experts' Profiles } & Case studies \\
\hline Interviewees & Role & $\begin{array}{l}\text { Building Project } \\
\text { Type(s) }\end{array}$ & Certification(s) \\
\hline E1 & Architect & Primary School & $\begin{array}{l}\text { BREEAM Excellent, } \\
\text { Passivhaus }\end{array}$ \\
\cline { 3 - 4 } & & Higher Education & BREEAM Outstanding \\
\hline E2 & Architect & School & Passivhaus \\
\hline E3 & Architect & Public Library & BREEAM Excellent \\
\hline E4 & Architect & College & BREEAM Excellent \\
\cline { 3 - 4 } & & Hospital & BREEAM Excellent \\
\hline E5 & & Higher Education & BREEAM Excellent \\
\hline E6 & Project Manager & Museum & BREEAM \\
\hline
\end{tabular}


Table 3: BREEAM Strategy against RIBA Plan of Work 2013 Stages - BIM Execution Plan Guide (example)

\begin{tabular}{|c|c|c|c|c|c|c|c|c|c|c|c|c|c|c|c|c|}
\hline \multicolumn{17}{|c|}{$\begin{array}{l}\text { BIM-based sustainability an alysis and the BREEAM rating system } \\
\text { (SuperBuildings 2011, BREF.AM 2012, Crawley et al. 2008, Azhax et al. 2011, Attia et al. 2009, Cinquemanjet al. 2010, RIBA 2013, CIC 2010, CIC 2013, Hardin 2009). }\end{array}$} \\
\hline \multicolumn{9}{|c|}{$\begin{array}{l}\text { Relationship between BIM-based sustainability an alysis \& } \\
\text { minimum stand ards by BREFAM rating level }\end{array}$} & \multicolumn{8}{|c|}{ RIBA Plan of Work 2013 Stages } \\
\hline Categories & $\begin{array}{l}\text { Weighting } \\
\text { \& Credits }\end{array}$ & BIM Use & $\begin{array}{l}\text { Responsible } \\
\text { Party }\end{array}$ & Priority & \begin{tabular}{|l|} 
Overlaps \& \\
Associations
\end{tabular} & $\begin{array}{l}\text { Standards \& } \\
\text { Documents }\end{array}$ & $\begin{array}{l}\text { Software } \\
\text { Resources }\end{array}$ & $\begin{array}{l}\text { Required } \\
\text { Evidence }\end{array}$ & $\begin{array}{c}0 \\
\begin{array}{c}\text { Strategic } \\
\text { Design }\end{array} \\
\end{array}$ & $\begin{array}{c}1 \\
\begin{array}{c}\text { Preparation } \\
\text { and Brief }\end{array} \\
\end{array}$ & $\begin{array}{c}2 \\
\text { Concept } \\
\text { Design }\end{array}$ & $\begin{array}{c}3 \\
\begin{array}{c}\text { Developed } \\
\text { Design }\end{array}\end{array}$ & \begin{tabular}{c|c|}
4 \\
Technical \\
Design
\end{tabular} & $\begin{array}{c}5 \\
\text { Construction }\end{array}$ & \begin{tabular}{|c|}
6 \\
$\begin{array}{c}\text { Handover } \\
\text { and Close }\end{array}$ \\
\end{tabular} & In Use \\
\hline $\begin{array}{l}\text { Ene 01 Reduction of } \\
\text { emissions }\end{array}$ & $0-10$ & $\begin{array}{l}\text { Analyse Energy } \\
\text { Performance }\end{array}$ & $\begin{array}{c}\text { Client/ Dasign } \\
\text { Team/ } \\
\text { Spacisilist } \\
\text { Consultant }\end{array}$ & High & Ene04 & 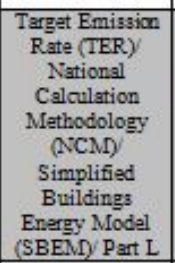 & $\begin{array}{c}\text { GBS/ EIO/ } \\
\text { HEED } \\
\text { ECOTECT/ } \\
\text { eQUEST/IES } \\
\text { VE }\end{array}$ & $\begin{array}{l}\text { Contract / } \\
\text { Design } \\
\text { Drawings }\end{array}$ & Evaluate & Plan (!) & Act & & & & & \\
\hline Ene 02 Energy monitoring & $0-1$ & & Design Team & High & $\mathrm{Man} 03$ & $\begin{array}{c}\text { CIBSE TMB39/ } \\
\text { Part L }\end{array}$ & & $\begin{array}{c}\text { Contract/ } \\
\text { Dessign } \\
\text { Draswings }\end{array}$ & Evaluate & Plan (1) & Act & & & & & \\
\hline Ene 03 External ligh ting & & $\begin{array}{l}\text { Generate } \\
\text { Extemal } \\
\text { Lighting } \\
\text { Strategy }\end{array}$ & Design Team & Low & Hes01 & 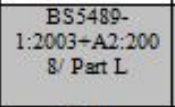 & $\begin{array}{c}\text { E10/ } \\
\text { ECOTECT/ } \\
\text { eQUEST/IES } \\
\text { VE }\end{array}$ & $\begin{array}{l}\text { Contract/ } \\
\text { Dasign } \\
\text { Drawings }\end{array}$ & Evaluate & Plan & Plan & Act & & & & \\
\hline $\begin{array}{l}\text { Ene 04 Low and zero } \\
\text { carbon technologies }\end{array}$ & $0-1$ & $\begin{array}{l}\text { Anslyse Energy } \\
\text { Performance }\end{array}$ & $\begin{array}{c}\text { Client/ Dasign } \\
\text { Team/ } \\
\text { Specialist } \\
\text { Consultant }\end{array}$ & High & $\begin{array}{l}\text { Man01/ } \\
\text { Man05// } \\
\text { Hea03/ } \\
\text { Ene01/ } \\
\text { Ene08 }\end{array}$ & $\begin{array}{c}\text { ISO } \\
\text { 14044:2006/ } \\
\text { Directive } \\
\text { 2009/28/EC } \\
\text { Part L } \\
\end{array}$ & $\begin{array}{c}\text { GBS/ E10/ } \\
\text { ECOTECT/ } \\
\text { eQUEST/IES } \\
\text { VE }\end{array}$ & $\begin{array}{l}\text { Feasibility Striy } \\
\text { Report } \\
\text { Simulation } \\
\text { Model Results }\end{array}$ & Evaluate & Plan (!) & Act & & & & & \\
\hline $\begin{array}{l}\text { Ene } 05 \text { Energy efficient ald } \\
\text { storage }\end{array}$ & & $\begin{array}{l}\text { Analyze Energy } \\
\text { Performance }\end{array}$ & Dasign Team & Medium & & \begin{tabular}{|c|} 
Commercial \\
Reffigeration \\
Code of \\
Conduct for \\
Reducing Cor- \\
bon Enissions \\
The Carbon \\
Trust \\
Refrigarstion \\
Road Map/ BS \\
EN 378-1/ Part \\
L
\end{tabular} & IES VE & $\begin{array}{c}\text { Building } \\
\text { Services } \\
\text { Enginear's } \\
\text { Calculations } \\
\text { Supplier's } \\
\text { Certificate }\end{array}$ & Evaluate & Plan & Plan & Plan & Act & & & \\
\hline $\begin{array}{l}\text { Ene 06 Energy efficient } \\
\text { transportation systems }\end{array}$ & & $\begin{array}{l}\text { Analyae Energy } \\
\text { Performance }\end{array}$ & & Medium & & $\begin{array}{l}\text { CIBSE Grida } \\
\text { D/Part L }\end{array}$ & & $\begin{array}{c}\text { Calculations } \\
\text { Report/ Contratt }\end{array}$ & Evaluate & Plan & Plan & Plan & Act & & & \\
\hline $\begin{array}{l}\text { Ene07 Energy efficient } \\
\text { laboratory systems }\end{array}$ & & $\begin{array}{l}\text { Analyse Energy } \\
\text { Performance }\end{array}$ & Design Team & Medium & Hea02 & \begin{tabular}{|c|} 
BS798:2001/ \\
BS EN $14175-$ \\
2 CIBSE Guide \\
B2 CIISE \\
TM46 / Part L
\end{tabular} & & $\begin{array}{l}\text { Manufacture's } \\
\text { Docomentation' } \\
\text { Modelling } \\
\text { Results Design } \\
\text { Taemm's } \\
\text { Corraspondence }\end{array}$ & Evaluate & Plan & Act & & & & & \\
\hline $\begin{array}{l}\text { Ene 08 Energy efficient } \\
\text { equipment }\end{array}$ & & $\begin{array}{c}\text { Anslyse Energy } \\
\text { Performance }\end{array}$ & $\begin{array}{l}\text { Client/ Dasign } \\
\text { Team }\end{array}$ & High & $\begin{array}{l}\text { Ene01/1/ } \\
\text { Ene04 }\end{array}$ & \begin{tabular}{c|} 
Capital \\
Allowance \\
Scheme Energy \\
Technology \\
Product List, \\
ETPL Energy \\
Star CIBSE \\
Gride TML50 \\
Part L \\
\end{tabular} & $\begin{array}{c}\mathrm{El} / \mathrm{DB} / \\
\mathrm{ECOTECT} / \\
\mathrm{ECUEST} / \mathrm{IES} \\
\mathrm{V} \\
\mathrm{VE}\end{array}$ & $\begin{array}{l}\text { Mamufacturers } \\
\text { product datsils/ } \\
\text { Life Cycle } \\
\text { Analysis Report }\end{array}$ & Evaluate & Plan & Plan & Plan & Act & & & \\
\hline Ene 09Drying space & & & & Low & & Part L & Revit & $\begin{array}{c}\text { Design } \\
\text { Drawings } \\
\end{array}$ & & & & & & & & \\
\hline
\end{tabular}


Table 4: LODs in building performance modelling

\begin{tabular}{|c|c|c|c|c|c|}
\hline $\begin{array}{l}\text { LOD (AIA, } \\
\text { 2013) }\end{array}$ & LOD (RIBA, 2013) & LOD (CIC, 2013) & $\begin{array}{l}\text { RIBA Plan of Work } 2013 \\
\text { Stage (RIBA, 2013) }\end{array}$ & Modelling Detail & Depth of Analysis \\
\hline LOD 100 & Outline (Out) & 1 - Brief & 1 - Preparation \& Brief & $\begin{array}{l}\text { Site location, preliminary positioning, preliminary } \\
\text { massing, layout (locate rooms \& volumes), } \\
\text { special requirements, performance standards } \\
\text { (natural ventilation, temperature range), } \\
\text { schedules, statutory requirements, user profiles }\end{array}$ & $\begin{array}{l}\text { Site conditions, critical surveys, } \\
\text { environmental \& ecological surveys, } \\
\text { topography, sustainability aspirations }\end{array}$ \\
\hline LOD 200 & Performance (P) & 2 - Concept & 2 - Concept Design & $\begin{array}{l}\text { Geometry, dimensions, elevations, massing, size, } \\
\text { form, volumes, orientation, master plan, } \\
\text { preliminary material specification, target U- } \\
\text { Values, glazing ratio for facades, shading depth \& } \\
\text { height, thermal mass, preliminary services } \\
\text { specification, }\end{array}$ & $\begin{array}{l}\text { Project scope, rules or thumb, } \\
\text { BREEAM modelling, preliminary } \\
\text { heating impact, individual early } \\
\text { assessment, information on materials, } \\
\text { sensitivity analysis, preliminary life } \\
\text { cycle carbon, preliminary life cycle } \\
\text { cost, preliminary code compliance }\end{array}$ \\
\hline LOD 300 & $\begin{array}{l}\text { Performance (P)/ Full: } \\
\text { Generic (F-G) }\end{array}$ & $\begin{array}{l}3 \text { - Developed } \\
\text { Design }\end{array}$ & 3 - Developed Design & $\begin{array}{l}\text { Definite window size/shape/location, materials, } \\
\text { accurate location on site \& orientation, accurate } \\
\text { building envelopes, compact surface areas, } \\
\text { accurate building services, numbering of } \\
\text { elements, ceiling, voids, plant location \&size, } \\
\text { duct size }\end{array}$ & $\begin{array}{l}\text { Estimation of quantities, embodied } \\
\text { carbon, complete BREEAM estimation }\end{array}$ \\
\hline LOD 350 & Full: Generic (F-G) & $\begin{array}{l}4-\text { Developed } \\
\text { Design }\end{array}$ & 3 - Developed Design & Detailed model & $\begin{array}{l}\text { Finalise BREEAM estimation, complete } \\
\text { sustainability assessment \& code } \\
\text { compliance }\end{array}$ \\
\hline LOD 400 & Full: Proprietary (F-P) & 4 - Production & 4 - Technical Design & $\begin{array}{l}\text { Construction details, daylighting \& artificial } \\
\text { lighting strategies \& controls, specification of } \\
\text { date, specification of products, definite contract, } \\
\text { maintenance strategy }\end{array}$ & $\begin{array}{l}\text { Air-tightness, handover strategy, } \\
\text { commissioning \& post-handover } \\
\text { strategy, life cycle assessment, } \\
\text { durability \& cost }\end{array}$ \\
\hline LOD 500 & Full: Proprietary (F-P) & $\begin{array}{l}5 \text { - Installation/ } 6 \\
\text { - As constructed }\end{array}$ & $\begin{array}{l}5 \text { - Construction/ } 6 \text { - } \\
\text { Handover \& Close }\end{array}$ & As-built validated model & $\begin{array}{l}\text { POE, monitoring of actual building } \\
\text { performance }\end{array}$ \\
\hline
\end{tabular}




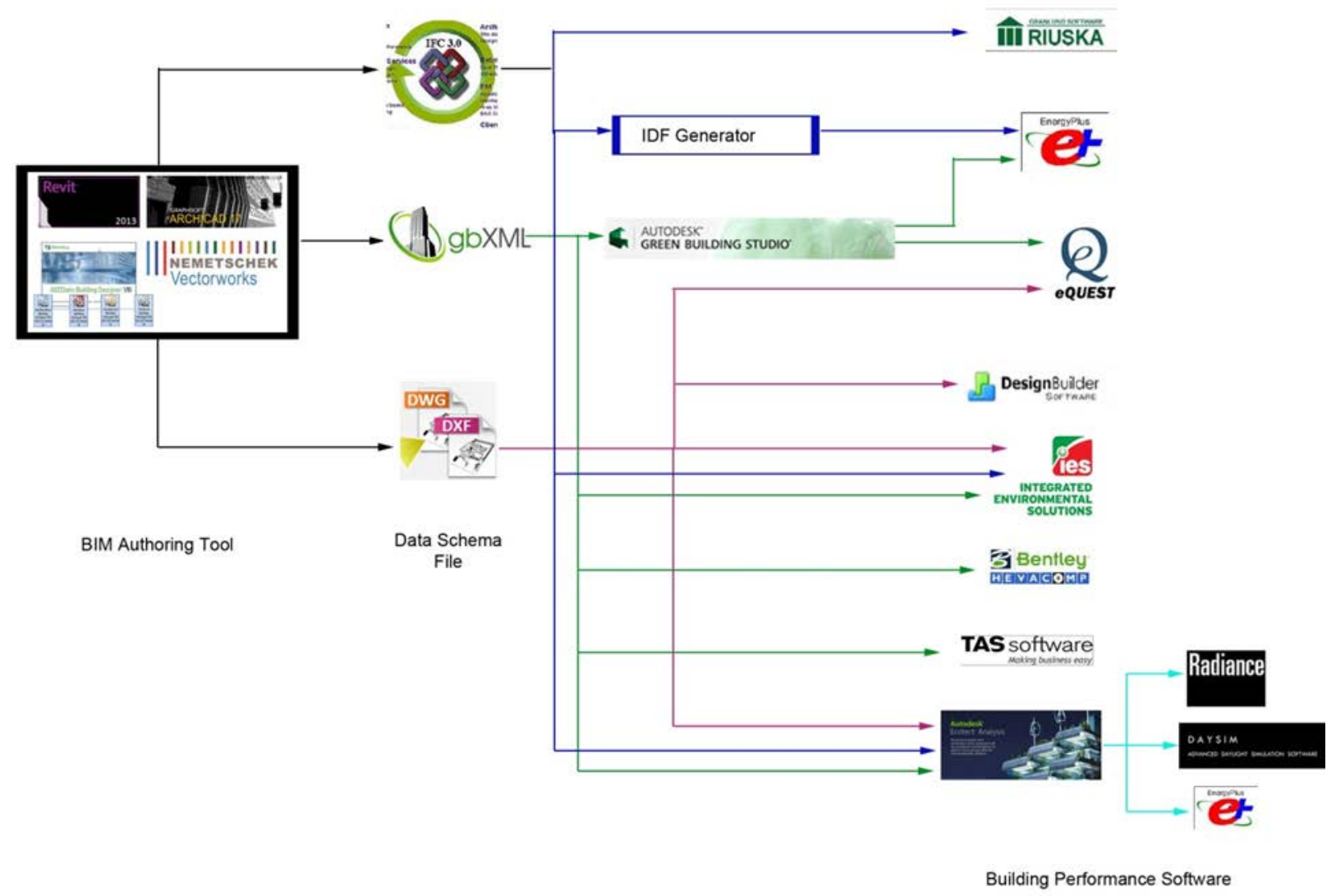

Figure 1: BIM-based information flows between software applications

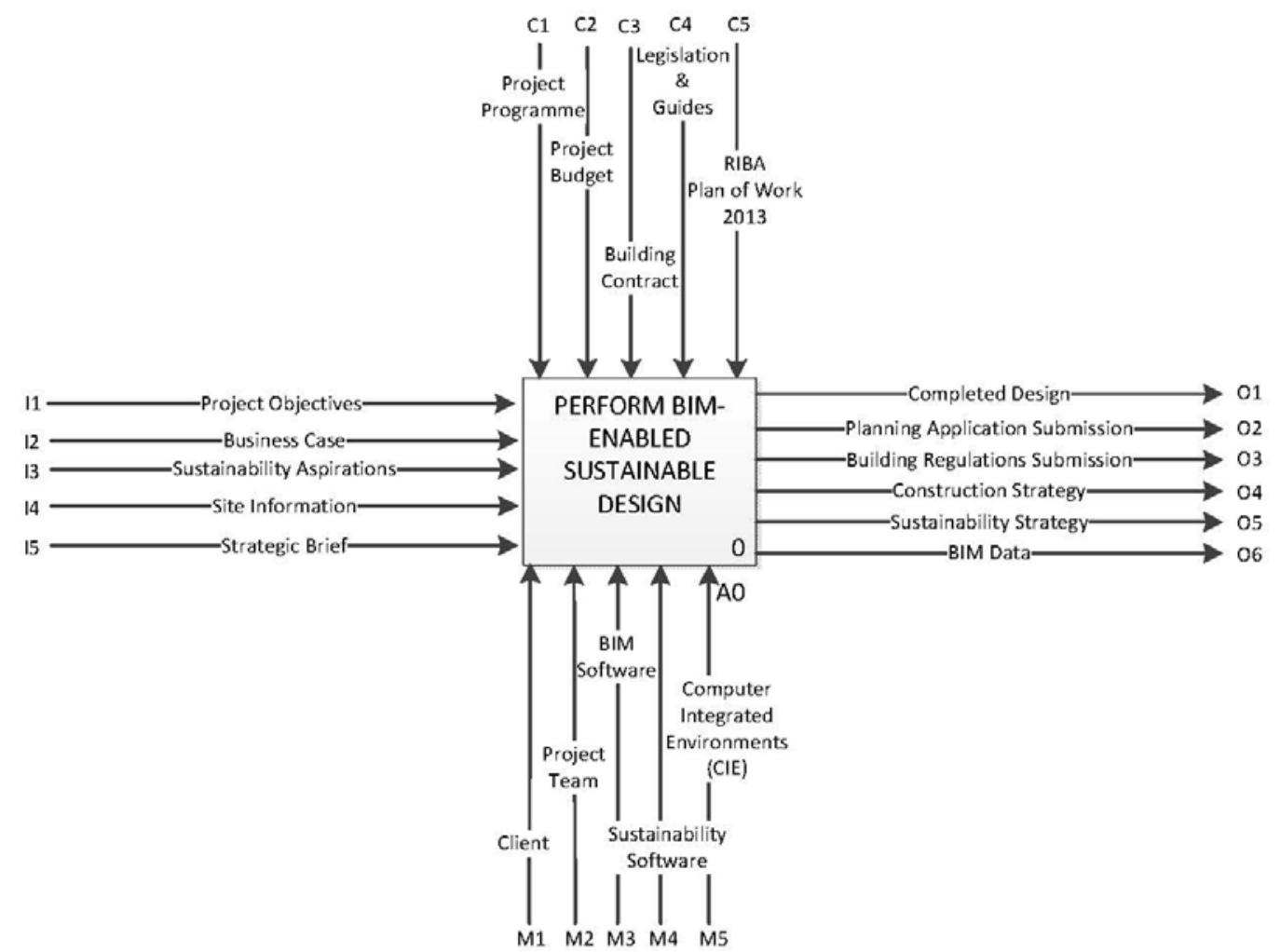

Figure 2: IDEF0 Parent Diagram (top-level) 


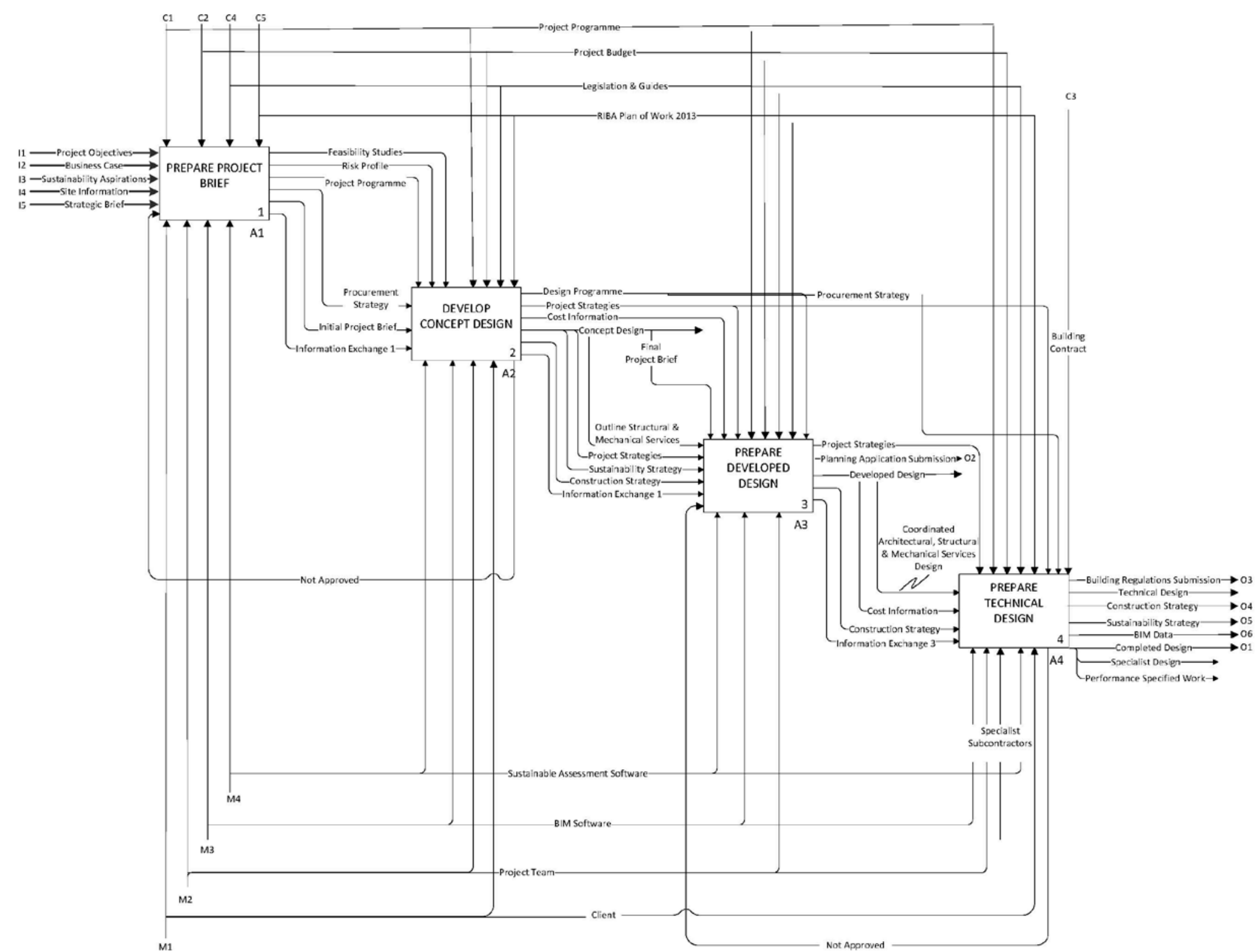

Figure 3: IDEF0 Child Diagram (decomposition) 




Figure 4: IDEF3 process-centred view decomposition diagram for Concept Design (A2) 